\title{
S5ynthesis
}

International Scientific Conference of IT and Business-Related Research

\section{OPTIMIZACIJA ELEMENATA SISTEMA BESPOSADNIH VAZDUHOPLOVA}

\section{OPTIMIZATION OF THE ELEMENTS OF UNMANNED AIRCRAFT SYSTEMS}

\author{
Dragan Vasiljević, Julijana Vasiljević \\ Univerzitet u Nišu, Elektronski fakultet, Niš, Srbija
}

\begin{abstract}
Apstrakt:
Do danas, većina letova koji su se realizovali „Sistemima za upravljanje besposadnim vazduhoplovima" izvršavali su se u nekontrolisanom delu vazdušnog prostora odnosno u klasi „G“ vazdušnog prostora i vazdušnom prostoru aerodroma gde su predstavljali opasnost za drugi saobraćaj koji je leteo u istom delu vazdušnog prostora. Trenutni sistemi za upravljanje besposadnim vazduhoplovima nisu $\mathrm{u}$ stanju da se bezbedno integrišu sa drugim korisnicima vazdušnog prostora, razlozi za to su su dvostruki - nemogućnost da se povinuje pravilima u kritičnim situacijama, i nedostatak SARPs - Standards and Recommended Practices, standardi i preporučena praksa specifična za besposadne vazduhoplove i njihove pomoćne sisteme.

Bez obzira da li je vazduhoplov sa posadom ili bez posade to ne utiče na njegov status kao vazduhoplova. Svaka kategorija vazduhoplova će imati potencijalno bespilotne verzije u budućnosti. Ova tačka je od centralnog značaja za sva dalja pitanja koja se odnose na „Sistemi za upravljanje besposadnim vazduhoplovima " $\mathrm{i}$ pruža osnovu za rešavanje plovidbenosti, kadrovsko licenciranje, standarde za razdvajanje, itd. U radu je opisan koncept sistema za upravljanje besposadnim vazduhoplovima, opisane su komponente sistema, način određivanja efikasnosti besposadnih sistema, operativne mogućnosti sistema besposadnih vazduhoplova, način određivanja manevarskog prostora uz pomoć fazi logike, upotreba modifikovanog „PSO“ algoritama za određivanje "pbest“ $\mathrm{i}$,gbest" pozicije u zadatom prostoru za „izvršni roj dronova“. Centralni deo rada biće opis modifikovanog „PSO“ algoritama za određivanje „pbest“ $i$ „gbest“ pozicije u zadatom prostoru za ,izvršni roj dronova".
\end{abstract}

\section{Ključne reči:}

besposadni vazduhoplov, sistem za upravljanje besposadnim vazduhoplovima, fazi logika, PSO algoritam.

\section{UVOD}

Opasnost iz vazduha se oduvek posmatrala kao posebna vojna situacija u kojoj su važile posebne mere maskiranja, fortifikacijskog utvrđivanja i protivvazdušne odbrane. Danas je ta opasnost značajno uvećana zbog letelica koje, zahvaljujući savremenoj tehnologiji, mogu selektivno da dejstvuju po tlu, birajući određene ciljeve za dejstvo. Opasnost ne predstavljaju samo avioni na velikim visinama, već i male, teško uočljive, naoružane bespilotne letelice, nazvane i „dronovi”.

Reč dron, dran, ili samoupravljiva naoružana bespilotna letelica danas se sve više spominje kad je reč o savremenim bor-

\section{Abstract:}

So far, most of the flights have been realized by means of " unmanned aircraft management systems" and carried out in uncontrolled airspace or work-in-class " $G$ " airspace and airport airspace, thus imposing danger to other traffic realized in the same part of the air space. The existing unmanned aircraft management systems are unable to safely integrate with other airspace users. That is mostly due to the the inability to comply with the rules in critical situations, and the lack of SARPs - Standards and Recommended Practices, standards and recommended practices specific to unmanned aircraft and their auxiliary systems.

The fact that the aircraft has or does not have its crew does not affect the status of an aircraft. Each category of aircraft will have potentially unmanned versions in the future. This is of vital importance for any further questions relating to "unmanned aircraft management systems" and provides the basis for the resolution of airworthiness, personnel licensing standards for separation, etc. This paper describes the concept of unmanned aircraft management system, its components, the method of determining the efficiency of unmanned aircraft systems, operational capabilities of unmanned aircraft systems, the methods of determining leeway with the help of the fuzzy - logic, using the modified "PSO" algorithms for determining "pbest" and "gbest" positions within the allotted space for "executive swarm of drones." The focal point of this paper will be the description of the modified "PSO" algorithms for determining "pbest" and "gbest" positions within the allotted space for "executive swarm of drones."

\section{Key words:}

unmanned aircraft, unmanned aircraft management systems, fuzzy-logic, PSO algorithm.

benim dejstvima. Sam pojam se na naš jezik može prevesti kao „trut” (pčela, obad) dok se može naći i prevod „zujalica”. Pojam se odomaćio u publicistici, medijima i u vojnim krugovima, a sve više zaokuplja i pažnju široke javnosti.

Bespilotne letelice se takođe koriste u civilnim strukturama, kao što su vatrogasna služba, civilna zaštita ili druge nevojne organizacije, na primer za nadzor cevovoda, kontrolu rečnih tokova, zahvaćenost teritorije poplavama ili zemljotresom i sl. Sve češće zamenjuju reportažne helikoptere za prenos sportskih nadmetanja kao što su biciklističke trke na velike daljine, maratoni ili automobilski reli. Uglavnom se bespilotne letelice upotrebljavaju u vojnim akcijama koje su opasne za posadu aviona. 


\section{ISTORIJSKA RETROSPEKTIVA}

Američki pronalazač Elmer Speri je 1909. godine započeo radove na konstruisanju žiroskopskih uređaja pomoću kojih bi kontrolisao stabilnost letelice u letu, što se smatra pretečom modernih inercijalnih navigacijskih sistema. Američka mornarica je pokazala određena interesovanja kako bi konstruisala „vazdušno torpedo" - preteču modernih krstarećih raketa. Kako bi usasvršili preciznost vazdušnog torpeda izvan veoma ograničenih sposobnosti prvih žiroskopa, kompanija Western Electric je razvila sistem radio upravljanja. Ove dve tehnologije, inercijalna navigacija i radio upravljanje, će formirati jezgro razvoja daljinski upravljivih letelica za narednih 80 godina.

Istorijski podaci nam kažu da je Nikola Tesla, naš slavni naučnik, 1915. godine opisao flotu bespilotnih borbenih vozila sa daljinskim upravljanjem. On je, kao što se zna, konstruisao i prvo plovno vozilo sa daljinskim upravljanjem.

Nova borbena tehnologija i proizvodnja samonavodećih raketa unapredila je ubojitost ove vrste letećih mašina. Broj tipova letelica je takođe porastao, od mini bespilotnih letelica do letelica raspona krila kao kod džambo džetova.

\section{KONCEPT SISTEMA ZA UPRAVLJANJE BESPOSADNIM VAZDUHOPLOVIMA}

Potpuno autonomne operacije besposadnih vazduhoplova, u današnjem vremenu predstavljaju veliki izazov u smislu konstrukcije i razvoja sistema koji bi omogućio da se tokom operacije autonomnih besposadnih vazduhoplova, u slučaju potrebe moglo upravljati u realnom vremenu tokom leta.

Daljinski-pilotiran vazduhoplovni sistem (Remotely-piloted aircraft system) je skup podesivih elemenata koji se sastoji od daljinski-pilotiranih vazduhoplova, njegove pridružene pilotske stanice, potrebnog komandno - kontrolnog sistema veza i svi drugi potrebni elementi sistema koji mogu biti potrebani kako bi u svakom trenutku tokom operacije letenja, mogli da utiču na manevarske sposobnosti vazduhoplova.

Iz napred navedenog osnovni elementi sistema za upravljanje besposadnim vazduhoplovima bili bi:

- Besposadni vazduhoplovi,

- Zemaljska stanica za kontrolu, nadzor i upravljanje,

- Telekomunikacioni sistem,

- Informacioni sistem,

- Servisna stanica,

- Energetska stanica,

- Dva vozila i

- Posada za kontrolu, nadzor, upravljanje i servisiranje sistema besposadnih vazduhoplova.

Bespilotni vazduhoplov (unmanned aircraft) je vazduhoplov u smislu člana 8. Konvencije o međunarodnom civilnom vazduhoplovstvu, namenjen izvođenju operacija bez pilota u vazduhoplovu, koji je ili daljinski upravljan ili unapred programiran i autonoman.

Osnovne komponente besposadnog vazduhoplova ( $\mathrm{u}$ daljem tekstu dron) su:

HARDVERSKI DEO

- Kostur drona (ram drona),

- Motori (broj i snaga motora zavisi od namene),

- Slop za elektronsku kontrolu brzine,

- Sklop za kontrolu leta drona,

- Propeleri,

- Baterije,
- Konektori,

- Telemetrijski slop i

- Senzori.

$\mathrm{Na}$ slici 1 dat je prikaz osnovih hardverskih komponenti drona.
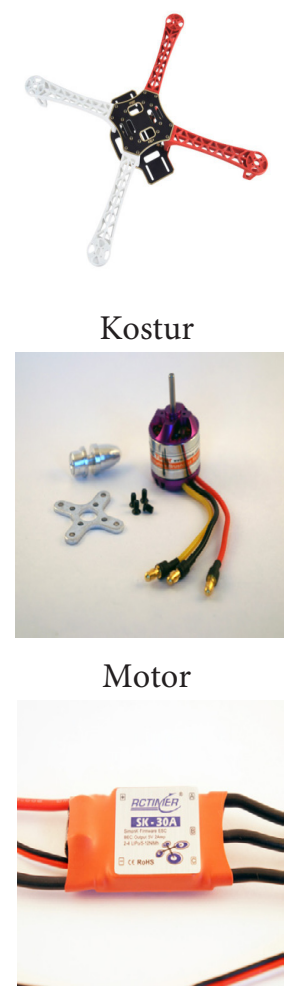

Sklop za kontrolu brzine

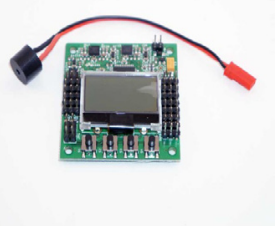

Sklop za elektroksku kontrolu leta drona

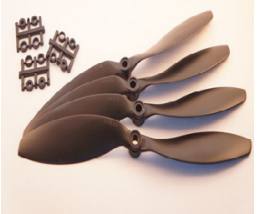

Propeleri

Slika 1. Prikaz osnovih hardverskih komponenti drona

\section{SOFTVERSKI DEO}

Se sastoji od međusobno povezanih i zavisnih modula koji omogućuju dronu orijentaciju u prostoru, stabilnost i sigurnost u letu, prepoznavanje zadatih objekata, komunikaciju i prenos podataka i informacija u realnom vremenu.

Osnovna zamisao autora ovog rada je razvoj sistema besposadnih vazduhoplova koji bi unapred bili programirani za rad u određenom prostoru, a uloga operatera bi se svodila na nadzor i eventualne reakcije na tok procesa u slučajevima kada postoje bezbednosni rizici.

Koncept optimizacije elemenata sistema besposadnih vazduhoplova sastoji se od sledećih koraka: 


\section{KORAK 1}

- određivanje efikasnosti „čestice“ ili drona.

- određivanje operativne mogućnosti „izvršnog roja“ ili dronova.

KORAK 2

- određivanje manevarskog prostora i kretanja „čestica“ ili dronova uz pomoć fazi logike.

\section{KORAK 3}

- implementacija modifikovani „PSO“ algoritama i određivanje „pbest“ i „gbest“ u zadatom prostoru za „izvršni roj"ili dronove.

KORAK 4

- predviđanje toka događaja - verovatnoću događaja primenom Bajesfove teoreme na ishod događaja.

\section{ODREĐIVANJE EFIKASNOSTI „ČESTICE“ ILI DRONA I OPERATIVNE MOGUĆNOSTI „IZVRŠNOG ROJA“ ILI DRONOVA}

Određivanje efikasnosti čestice ili drona data je prema sledećoj formuli:

$$
E_{b s}=E_{o f}(v) \cdot \sqrt{E_{u} \cdot E_{z}}
$$

$\mathrm{E}_{\mathrm{bs}}$ - efikasnost sistema besposadnih vazduhoplova,

$\mathrm{E}_{\mathrm{of}(\mathrm{V})}$ - efikasnost osnovne funkcije (za dronove to su manevarske mogućnosti ili efikasnost prikupljanja podataka),

$\mathrm{E}_{\mathrm{u}}$ - efikasnost upravljanja (informacionim i sistemima za upravljanje) i

$\mathrm{E}_{\mathrm{z}}$ - efikasnost zaštite.

Kada je različita značajnost uticaja spoljnih uslova, upravljanja i zaštite na efikasnost sistema besposadnih vazduhoplova, onda se definišu različiti koeficijenti značajnosti, tako da matematički izraz ima sledeći oblik:

$$
E_{b s}=\omega_{1} E_{o f}(v) \cdot \sqrt{\omega_{2} E_{u} \cdot \omega_{3} E_{z}}
$$

Posle dobijenih rezultata kojim se određuje efikasnost čestice ili drona, određujemo operativne mogućnosti sistema za upravljanje besposadnim vazduhoplovima prema sledećoj formuli:

$$
B_{m}=E_{b s} \cdot K_{b u}
$$

gde su:

$\mathrm{B}_{\mathrm{m}}$ - operativne mogućnosti sistema za upravljanje besposadnim vazduhoplovima i

$\mathrm{K}_{\mathrm{bu}}$ - koeficijent bitnih uslova.

Koeficijent bitnih uslova određujemo prema sledećoj formuli:

$$
K b u=\sqrt[n]{K v l j \cdot K v d \cdot K p d \cdot K b p \cdot K l a \cdot K f i \cdot K u d \cdot \ldots K n}
$$

Gde je:

$\mathrm{K}_{\mathrm{vlj}}$ - koeficijent vrednosti ljudstva, koji treba da uračuna niz kvalitativnih svojstava, kao što su obučenost, iskustvo i slično,

$\mathrm{K}_{\mathrm{vd}}$ - koeficijent vida delovanja,

$\mathrm{K}_{\mathrm{pd}}$ - koeficijent

Kbp - koeficijent podrške,

$\mathrm{K}_{\mathrm{la}}$ - koeficijent logističke autonomije,

$\mathrm{K}_{\mathrm{fi}}$ - koeficijent funkcionalne ispravnosti,

$\mathrm{K}_{\mathrm{ud}}$ - koeficijent uslova delovanja $\mathrm{i}$

$\mathrm{K}_{\mathrm{n}}$ - n-ti koeficijent.

Na kraju se izračunava ukupna mogućnost sistema za upravljanje besposadnim vazduhoplovima prema sledećoj formuli:

$$
B_{m s p v}=B_{n} \cdot n \cdot K_{u c}
$$

Gde je:

$$
\begin{aligned}
& \mathrm{B}_{\mathrm{m}} \text { - operativne mogućnosti sistema za upravljanje bes- } \\
& \text { posadnim vazduhoplovima, } \\
& \mathrm{n} \text { - broj dronova u operativnom radu i } \\
& \mathrm{K}_{\mathrm{uc}} \text { - koeficijent učešća (angažovanosti) u operaciji. }
\end{aligned}
$$

Na ovaj način određujemo sastav ili „kvantitativnu i kvalitativnu“ vrednost izvršnog roja, što je bitno za određivanje namene (čestica) izvršnog roja.

\section{ODREĐIVANJE MANEVARSKOG PROSTORA I KRETANJA „ČESTICA“ ILI DRONOVA UZ POMOĆ FAZI LOGIKE}

Izbor neizrazite logike u projektovanju sistema veštačke inteligencije za upravljanje bezposadnim vazduhoplovima se nameće kao logičan, s obzirom na to da je prikaz znanja odnosno iskustva moguće izraziti sudovima iskazanim u obliku pravila ako/onda (if/then).

To znanje se unutar sistema neizrazite logike po pravilu konvertira u izlazne vrednosti kroz tri faze:

- Fuzikacija,

- Neizrazito zaključivanje i

- Defuzikacija.

Proces fuzikacije predstavlja postupak pridruživanja realnih vrednosti ulaznih varijabli odgovarajućem skupu realnih vrednosti u intervalu od 0 do 1 , a na osnovu pripadnosti ulazne vrednosti nizu odgovarajućih funkcija, tzv. funkcija pripadnosti. Funkcija pripadnosti predstavlja odnos i grafički prikaz distribucije nivoa istinitosti pojedinih ulaznih vrednosti. Zatim nastupa proces donošenja odluka, na osnovu ako/onda (if/then), s nizom pravila koja su određena upravo na iskustvenom znanju. $\mathrm{Na} \mathrm{kraju,} \mathrm{u} \mathrm{procesu} \mathrm{defuzikacije,} \mathrm{vrednosti} \mathrm{takvih} \mathrm{odluka,} \mathrm{do-}$ bijene postupkom neizrazitog zaključivanja, se preobražavaju u precizne izrazite vrednosti koje će se iskoristiti kao upravljačka naredba u odgovarajućem upravljačkom sistemu.

Kako bi se bespoasadnim vazduhoplovom autonomno upravljalo u trodimenzionalnom prostoru u stabilnom letu, potrebno je upravljati sa dva skupa upravljačkih elemenata. Prvi skup upravljačkih elemenata je skup upravljačkih površina pomoću kojih letelica ostvaruje okrete u sve tri ose, a drugi skup je pogonska grupa koja omogućuje da aerodinamičke površine ostvaruju stabilano i konstantano penjanje ili poniranje. 
Upravljanje bezposadnim vazduhoplovom u definisanom segmentu unutar trodimenzionalnog prostora, moguće je izraditi i prikazati kao jednostavan simulacijski model. Za takvu simulaciju, pogodno je „MATLAB“ okruženje, koje poseduje odgovarajući modul za modeliranje sistema neizrazite logike kao što je Fuzzy Logic Toolbox.

\section{IMPLEMENTACIJA MODIFIKOVANI „PSO“ ALGORITAMA I ODREĐIVANJE „PBEST“ I „GBEST“ U ZADATOM PROSTORU ZA „IZVRŠNI ROJ“ ILI DRONOVE}

Algoritam roja čestica (Particle Swarm Optimization) otkriven je sasvim slučajno, pri pokušaju da se na računaru simulira kretanje jata ptica. Craig Reynolds (1978) u svom radu posmatra jato ptica kao sistem čestica, gdje svaka čestica (tj. ptica) svoj let ravna prema sledećim pravilima:

- izbjegavanje kolizije s bliskim pticama,

- usklađivanje brzine leta s bliskim pticama te

- pokušaj ostanka u blizini drugih ptica.

Inspirisani ovim i sličnim radovima, Eberhart i Kennedy shvataju da se takav sistem može koristiti kao optimizator, te svoje ideje objavljuju 1995. godine u dva temeljna rada (Kennedy \& Eberhart, 1995; Eberhart \& Kennedy, 1995). Eberhart et al. (1996) objavljuju knjigu o uporabi algoritma roja čestica kao univerzalnog optimizacijskog alata.

Kennedy i Eberhart (1997)objavljuju rad o primeni algoritma za rad nad diskretnim domenama. Sam algoritam u određenoj meri inspirisan je i sociološkim interakcijama između pojedinaca u populaciji, gde svaki pojedinac pamti svoje do tada pronađeno najbolje rešenje problema, te ima uvid u najbolje pronađeno rešenje svojih suseda, te pretraživanje usmerava uzimajući u obzir obe komponente.

PSO algoritam radi tako što u prostoru za pretragu simultano održava nekoliko (broj zavisi od veličine populacije) kandidata za rešenje. $U$ toku svake interacije algoritma svaki kandidat za rešenje evaluira se pomoću funkcije koja se optimizira, na taj način se određuje fitnes najboljih kandidata, svaki od kandidata za rešenje može se zamisliti kao čestica (particle) koji leti kroz prostor za pretragu.

PSO algoritam se sastoji od tri koraka koji se neprekidno ponavljaju dok ne bude ispunjen neki od kriterijuma za zaustavljanje.

1. Određivanje fitnesa svake čestice,

2. Ažuriranje individualno i globalno najboljeg fitnesa i položaja i

3. Ažuriranje brzine i položaja svake čestice.

Izračunavanje fitnesa vrši se evaluiranjem funkcije koja se optimizira u tački koju određuje kandidat za rešenje. Individualni i globalni najbolji fitnesi ažuriraju se poređenjem novo-izračunatih fitnesa sa do sada najboljimindividualnim i globalnim fitnesima i zamenom najboljeg fitnesa i položaja ako je potrebno. Korak 3 algoritma u kojem se ažuriraju brzine i položaji čestica je odgovoran za optimizacione sposobnosti PSO metode.

Brzina svake čestice se ažurira na osnovu sledeće formule:

$$
v_{i}(t+1)=\omega v_{i}(t)+c_{1} r_{1}\left[\widehat{x_{i}}(t)-x_{i}(t)\right]+c_{2} r_{2}\left[g(t)-x_{i}(t)\right]
$$

Parametre $c_{1}, c_{2}$ i $\omega$ određuje korisnik. Vrednosti $r_{1}$ i $r_{2}$ $\left(0 \leq r_{1} r_{2} \leq 1\right)$ su slučajne i ponovo se generišu pri svakom ažuriranju brzina. Sa $\widehat{x_{i}}(t)$ obeležen je položaj individualno najbolje čestice $i \mathrm{u}$ trenutku $\mathrm{t}$, a $g(t)$ označava položaj najbolje čestice $\mathrm{u}$ trenutku (t). U jednačini za ažuriranje brzine svaki od tri člana ima različitu ulogu u PSO algoritmu. Prvi član $\omega v_{1}(t)$ je inercijalna komponenta i ona je odgovorna za kretanje čestice u pravcu u kojem se i kretala. Vrednost inercijalnog kojeficijenta $\omega$ obično varira između 0.8 i 1.2. Kojeficijent $\omega$ možemo menjati u toku algoritma. Često želimo da na početku pospešimo istraživanje prostora za pretragu dok prikraju pretrage želimo da ubrzamo konvergenciju. U tom slučaju koristimo formulu koja u svakoj interaciji linearno smanjuje vrednost $\omega$.

$$
\omega=0.9-i \cdot(0.5 / \text { noi })
$$

U gornjoj formuli noi označava broj interacija dok je sa $i$ obeležena trenutna interacija.

Drugi član u formuli:

$$
c_{1} r_{1}\left[\widehat{x}_{i}(t)-x_{i}(t)\right]
$$

naziva se kognitivna komponenta i ona predstavlja memoriju čestice i utiče na to da se čestica vraća na one oblasti prostora za pretragu u kojima je imala individualno najbolji fitnes. Kognitivni koeficijent $c_{1}$ obično ima vrednost 2 i utiče na veličinu koraka kojom se čestica primiče svojoj najboljoj dosadašnjoj vrednosti.

Treći član u formuli:

$$
c_{2} r_{2}\left[g(t)-x_{i}(t)\right]
$$

naziva se socijalna komponenta i utiče da se čestica primakne najboljem kandidatu koji je roj do sada pronašao. Socijalni koeficijent $c_{2}$ ima vrednost oko 2 .

Zbog slučajnih vrednosti $r_{1}$ u kognitivnoj komponenti i $r_{2} \mathrm{u}$ socijalnoj komponenti, pomenuta dva člana imaju stohastički uticaj na ažuriranje brzine.

Zbog ove stohastičke prirode svaka od čestica se kreće u polu-slučajnim maniru, ali pod značajnim uticajem sopstvenog najboljeg položaja i položaja globalno najbolje čestice. U cilju sprečavanja čestice da se udalje od granica prostora za pretragu koristi se tehnika ograničavanja brzine (velocity clamping) kako bi se ograničila brzina svake čestice.

Nakon izračunavanja brzine svake čestice, položaj svake čestice se ažurira na osnovu brzine i prethodnog položaja čestice:

$x_{i}(t+1)=x_{i}(t)+v_{i}(t+1)$

Opisani postupak se ponavlja sve dok se ne zadovolji neki kriterijum za zaustavljanje.

Pseudo kod PSO algoritama:

For (svaka čestica)

Inicijalizacija čestice

end

Do

For (svaka čestica)

Izračunati fitnes

Ako je fitnes bolji od do sada najboljeg fitnesa jedinke pBest najbolju vrednost zameniti trenutnom vrednošću

end

Izabrati česticu sa najboljim fitnesom za gBest

For (svaka čestica)

1. Izabrati brzinu čestice u sledećem trenutku

2. Ažurirati položaje čestica

end

Dok nije zadovoljen kriterijum za izlazak. 
Kod PSO algoritama potrebno je uvesti faktor korekcije kako bi se obezbedila konvergencija algoritma:

$$
v_{i}(t+1)=K\left(v_{i}(t)+c_{1} r_{1}\left[\widehat{x}_{i}(t)-x_{i}(t)\right]+c_{2} r_{2}\left[g(t)-x_{i}(t)\right]\right)
$$

Gde je:

$$
\begin{aligned}
& K=\frac{2}{\left|2-\varphi-\sqrt{\varphi^{2}-4 \varphi}\right|} \\
& \varphi=c_{1}+c_{2}, \varphi>4
\end{aligned}
$$

U tipičnom slučaju korišćenja faktora korekcije, $\varphi$ se postavlja da bude 4.1 tako da je konstantni faktor $K=0.729$. To znači da se brzina u prethodnom trenutku množi sa 0.729 , a ostala dva člana sa $0.729 * 2.05=1.49445$ (puta jedna slučajna vrednost koja je između 0 i 1).

$\mathrm{U}$ četvrtom koraku uz primenu Bajesove teoreme, u globalnom smislu vršimo predikciju ishoda operativne upotrebe dronova.

\section{ZAKLJUČAK}

Ključni faktor za bezbednu integraciju sistema besposadnih vazduhoplova u vazdušni prostor će biti njihova sposobnost da odgovore kao vazduhoplovi sa posadom. Većina ovih sposobnosti će biti predmet tehnološkog razvoja sposobnosti besposadnih vazduhoplova.

U radu je opisan način na koji određujemo koliki broj „čestica“ ili dronova je potreban za realizaciju zadataka u definisanom prostoru, za svaku „česticu“ ili dron prikazan je način na koji određujemo manevarske sposobnosti i rejon (globalne granice prostora) i na kraju je opisana optimizacija pomoću „PSO“ algoritma.

Siguran rad sa besposadnim vazduhoplovima podrazumeva da vođe daljinski upravljanih vazduhoplova ili operatori sistema „UAS“ imaju istu obavezu kao i piloti vazduhoplova i kontrolo- ri letenja, za poznavanje zakona o vazdušnom saobraćaju, poznavanje letnih performansi vazduhoplova, obavezu planiranja leta, obavezu licenciranja, poznavanje osnova vazduhoplovne meteorologije, navigacije, operativnih procedura, poznavanje osnovnih principa teorije letenja i radiotelefonije.

\section{LITERATURA}

Clerc, M. (1999). The swarm and the queen: towards a deterministic and adaptive particle swarm optimization.In Proc. 1999 Congress on Evolutionary Computation, Washington, DC, pp. 1951-1957. Piscataway, NJ: IEEE Service Center.

de Oca, M.A.M., Stützle, T., Birattari, M., \& Dorigo, M. (2009). Frankenstein's PSO: A Composite Particle Swarm Optimization Algorithm. IEEE Transaction on Evolutionary Computation, 13(5), 1120-1132. DOI: 10.1109/TEVC.2009.2021465

Eberhart, R.C., \& Kennedy, J. (1995). A new optimizer using particle swarm theory. In Proceedings of the Sixth International Symposium on Micro Machine and Human Science, Nagoya, Japan, pp. 39-43. Piscataway, NJ: IEEE Service Center.

Eberhart, R.C., \& Shi, Y. (2001). Particle swarm optimization: developments, applications and resources. In Proc. Congress on Evolutionary Computation 2001, Seoul, Korea, pp. 8186. Piscataway, NJ: IEEE Service Center.

Eberhart, R.C., Simpson, P.K., \& Dobbins, R.W. (1996). Computational Intelligence PC Tools. Boston, MA: Academic Press Professional.

Kennedy, J., \& Eberhart, R.C. (1995). Particle swarm optimization. In Proceedings of IEEE International Conference on Neural Networks, pp. 1942-1948.

Kennedy, J., \& Eberhart, R.C. (1997). A discrete binary version of the particle swarm algorithm. In Proceedings of the IEEE 1997 International Conference on Systems, Man and Cybernetics, pp. 4104-4109.

Reynolds, C.W. (1987). Flocks, herds and schools: A distributed behavioral model. Computer Graphics, 21(4), 25-34. 